\title{
Inclusion complex of steroidal heterocyclic compounds with cyclodextrins in aqueous solution and in the solid state
}

\author{
Carmen Topala ${ }^{\mathrm{a}}$, Gabriela Ionita, ${ }^{\mathrm{a}}$ Viorica Meltzer, \\ Elena Pincu, ${ }^{b}$ and Constantin Draghici ${ }^{c}$ \\ ${ }^{a}$ University of Pitesti, Department of Chemistry, Tg.Vale Str. Nr. 1, Pitesti 0300, Romania \\ ${ }^{\mathrm{b}}$ University of Bucuresti, Faculty of Chemistry, Bd. Carol I 13, Bucharest, 70346, Romania \\ ${ }^{c}$ Institute of Organic Chemistry, NMR Department, Spl. Independentei 202B, Bucharest
} 15 PO Box 258, Romania

(received 23 Aug 2001; accepted 06 Apr 2002; published on the web 14 Apr 2002)

\begin{abstract}
The complex formation of five steroidal heterocyclic compounds (1-5) with $\beta$-cyclodextrin and hydroxypropyl- $\beta$-cyclodextrin was investigated in aqueous solution and in solid state in order to find the strenght of interaction. The complex formation of these steroidic compounds with CDs in aqueous solution was studied by solubility analysis and ultraviolet absorption methods. For the study of solid state interaction, solid complexes were prepared by the solvent evaporation method and complexes obtained were analysed by thermal analysis. Also, synthesis, NMR and IR data of the new steroidic compounds 1,2, and 3are presented.
\end{abstract}

Keywords: $\beta$-Cyclodextrin, heterocyclic steroids, inclusion complex, solid state

\section{Introduction}

Steroids are natural compounds with a great variety of different biological functions, for example they interfere in digestion and in solubilisation of fats (colic acid), they are constituents of cell membranes (cholesterol), or can be found as hormones androgens (corticoids). ${ }^{1}$ Steroids are highly water insoluble and they are transported as complex by globulins, glycoproteins and albumin. ${ }^{2}$ There are numerous reports and reviews describing the ability of cyclodextrins (CDs) to form inclusion complexes with many poorly water solubility molecules, including steroids. ${ }^{1,3}$ Upon complexation by CDs, steroid solubility increses strongly and their pharmaceuticaly characteristics are enhanced. ${ }^{4} \beta$-cyclodextrin $(\beta-C D)$ is one of natural $C D$ s formed by enzymatic degradation of starch, and contains seven $\alpha$-D-glucopyranose rings connected by $1,4^{\prime} \mathrm{O}$ glycosidic bonds. Hydroxypropyl- $\beta$-cyclodextrin (HPB) is a chemical modified $\beta-\mathrm{CD}$ with a higher water solubility. CDs have a truncated cone geometry with hydrophobic inside character, because it is lined by $\mathrm{C}-\mathrm{H}$ hydrogens and ether like oxygens, and a hydrophil character of rims of 
the cone due to primary and secondary hydroxyls. These geometry explain their ability to form inclusion complexes with organic molecules. ${ }^{5}$

Table 1. The steroid compounds 1-5 used in the present paper
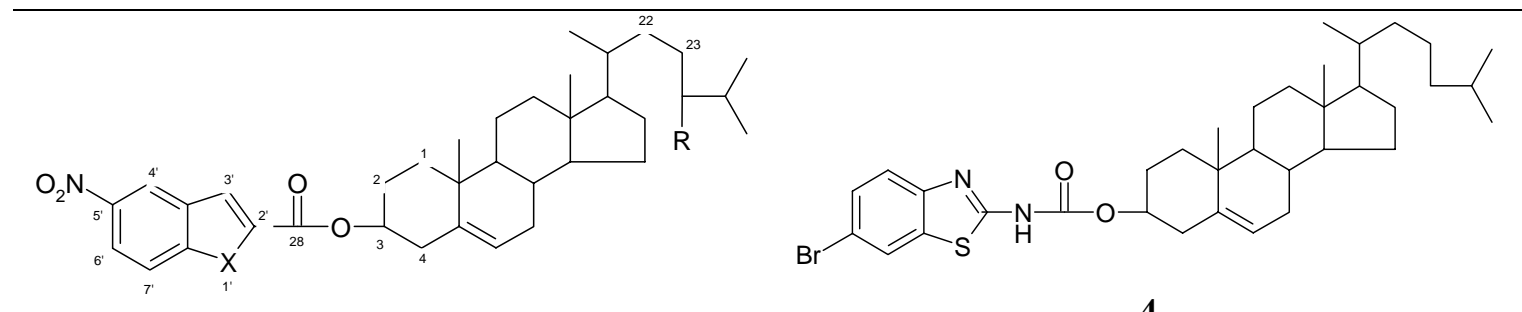

$$
\begin{gathered}
\mathrm{X}=\mathrm{S}, \mathrm{R}=\mathrm{Et}, \mathrm{C}_{22}-\mathrm{C}_{23}=\text { double bond } \\
\mathbf{2} \\
\mathrm{X}=\mathrm{SO}_{2}, \mathrm{R}=\mathrm{Et}, \mathrm{C}_{22}-\mathrm{C}_{23}=\text { double bond } \\
\mathbf{3} \\
\mathrm{X}=\mathrm{SO}_{2}, \mathrm{R}=\mathrm{Et}
\end{gathered}
$$

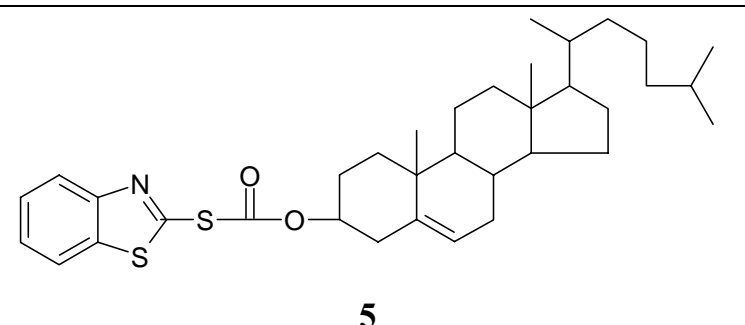

The purpose of present study is to investigate the inclusion complexes of five heterocyclic steroids (presented in Table 1, stigmasteryl-5'-nitrobenzo[b]-thiophen-2'-carboxylate (1), stigmasteryl-5'-nitrobenzo[b]-thiophensulphone-2'-carboxylate (2), citosteryl-5'-nitrobenzo[b]thiophensulphone-2'-carboxilate (3), cholesteryl-6-bromobenzothiazolyl carbamate (4) and cholesteryl-mercaptobenzothiazolyl-2-carbamate (5)) with $\beta$-CD and HPB, using the solubility method and UV-Vis technique for the complex formation in aqueous solution, and the DSC technique for the solid complexes.

\section{Results and Discussion}

\section{Thermal analysis study of complexation}

Complexes of the steroids 1-5 with $\beta$-CD and HPB were examined by DSC measurement and compared with corresponding pure steroids. The DSC of the compound $\mathbf{1}$, of the complex of 1 with $\beta-\mathrm{CD}$, and of the complex of 1 with $\mathrm{HPB}$, was shown in Figure 1-A, B, and C, respectively. The peak at $515 \mathrm{~K}$ from diagram $\mathrm{A}$ corresponds to the melting temperature of the compound 1 .The interactions of 1 with $\beta-\mathrm{CD}$ and HPB are accompanied by the shift of the peaks to $518 \mathrm{~K}(\mathrm{~B})$ and respectively $517 \mathrm{~K}(\mathrm{C})$. Figure 2 shows the DSC thermograms of the compound 2 (A) and also of the complexes with $\beta-\mathrm{CD}$ (B) and HPB (C). The melting point of pure compound $\mathbf{2}$ is ilustrated by the peak at $497 \mathrm{~K}$ in thermogram A. The interactions of 2 with both $\beta-\mathrm{CD}$ and HPB lead to the appearance of some peaks at temperature higher than $573 \mathrm{~K}$. The 
greater temperature shift of the thermal peaks for the $\beta$-CD-2 and HPB-2 complexes proves the interaction between 2 and CDs. Figure 3 shows the DSC thermograms for the compound 3 (A) and it complexes with $\beta-\mathrm{CD}(\mathrm{B})$ and HPB (C). Thermogram A presents a peak around $480 \mathrm{~K}$ corresponding to the melting point of the compound 3 . Thermograms $\mathrm{B}$ and $\mathrm{C}$ show some peaks at temperature higher than $573 \mathrm{~K}$. As in the case of the compound 2 , these shifts prove the interactions of the CDs with the steroidic compound. Figure 4 shows the thermograms for the compound 4 and their solid complexes with $\beta-C D$ and HPB. Thermograms A shows a weak peak near the peak which corresponding to the melting point of of $\mathbf{4}$, followed by an exoterm peak. These peak correspond to the blue phase of compound 4 . All these peaks from thermogram A disappear in thermograms B and $\mathrm{C}$ at $540 \mathrm{~K}$, but are present at $580 \mathrm{~K}$. Thermograms obtained for compound 5 and corresponding complexes are presented in Figure 5. The melting point of 5 is $542 \mathrm{~K}$. After this temperature the thermogram A has not another peak. Thermogram B of system $\beta$-CD-5 shows some peaks between 580 and $588 \mathrm{~K}$; thermogram $\mathrm{C}$ corresponding to HPB-5 system presents few peaks around $591 \mathrm{~K}$. The results presented above indicate that steroid-CDs complexes exist in solid phase.

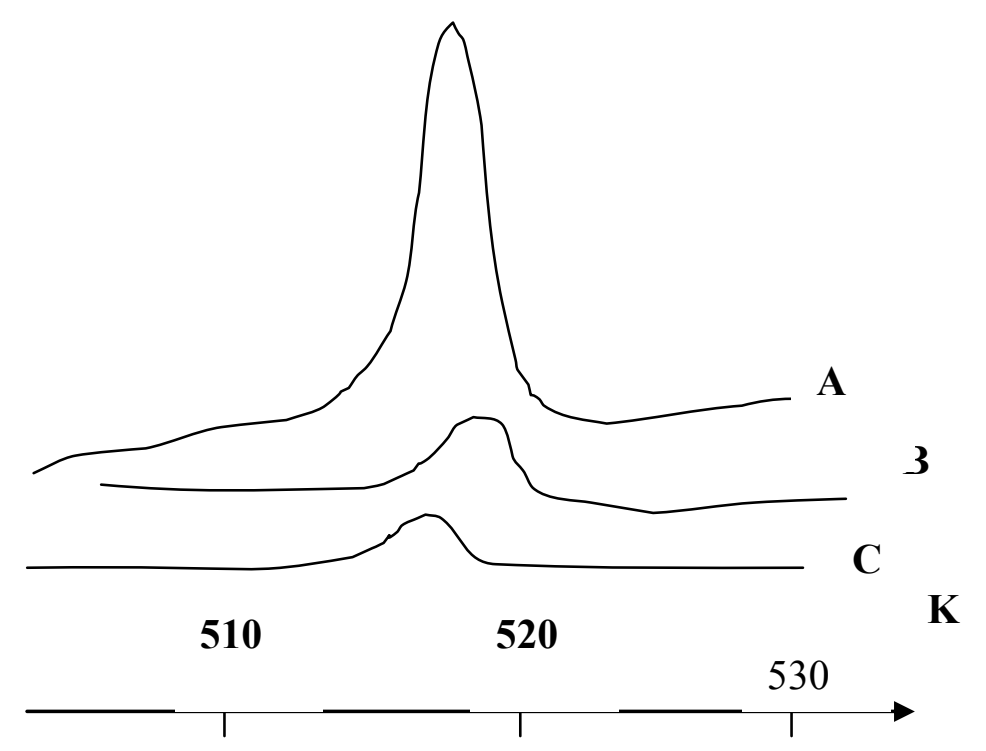

Figure 1. DSC thermograms of compound 1 (A) , $\beta$-CD-1 complex (B), and HPB-1 complex (C). 


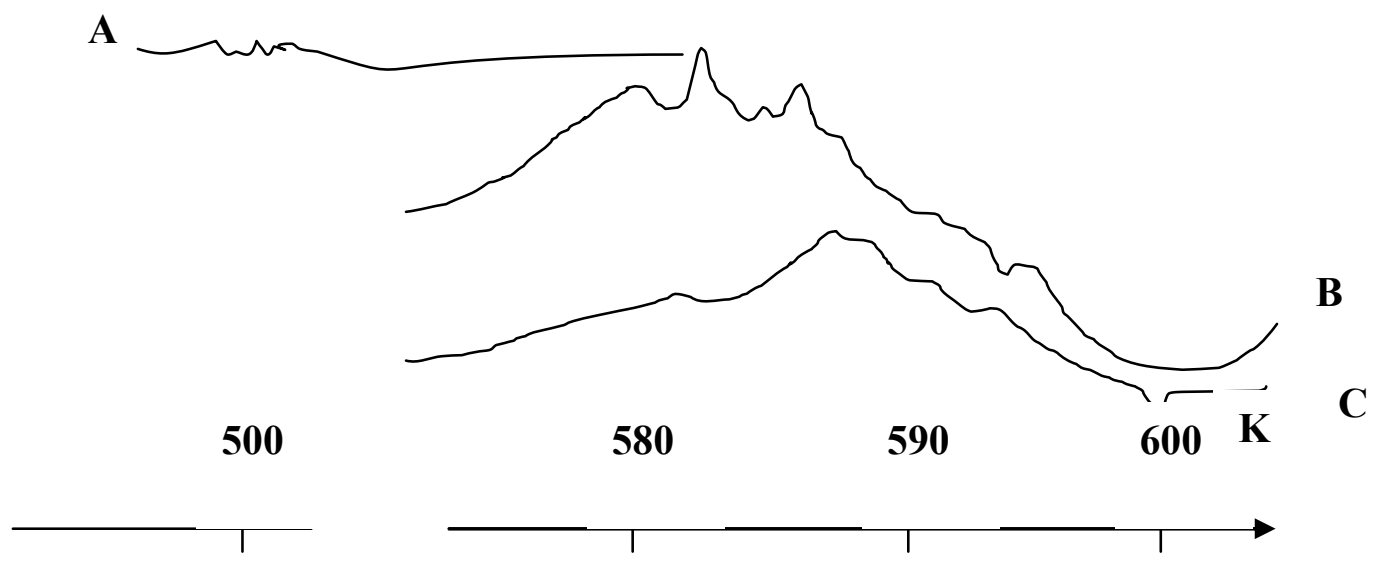

Figure 2. DSC thermograms of compound 2 (A), $\beta$-CD-2 complex (B), and HPB-2 complex (C).

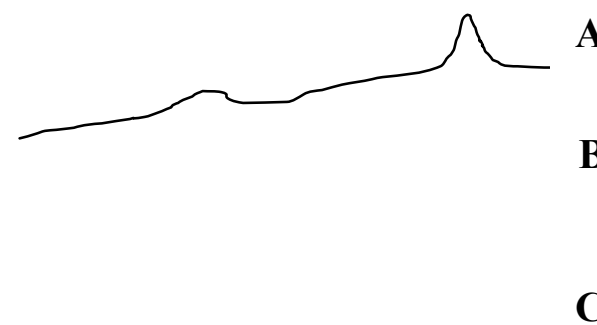

500

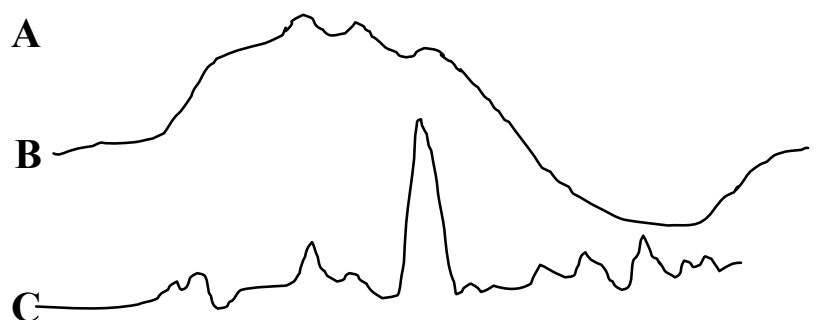

$590 \quad 600 \mathrm{~K}$

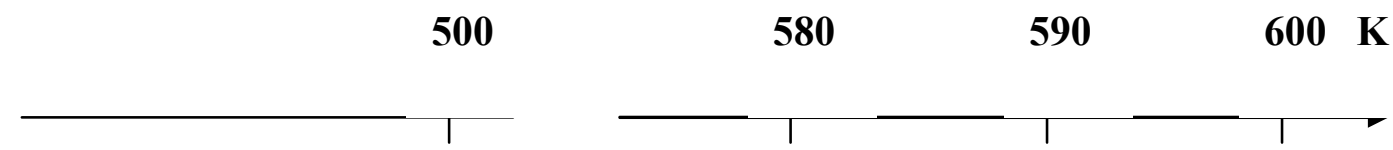

Figure 3. DSC thermograms of compound 3 (A) , $\beta-C D-3$ complex (B), and HPB-3 complex (C).

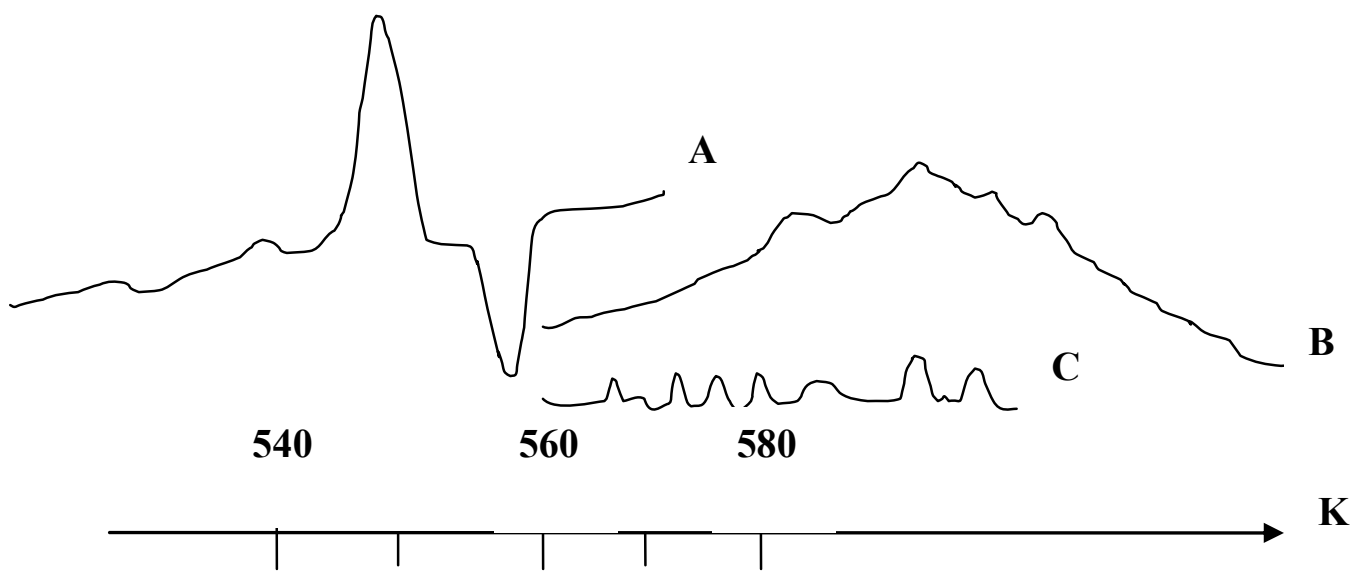

Figure 4. DSC thermograms of compound 4 (A) , $\beta-C D-4$ complex (B), and HPB-4 complex. 


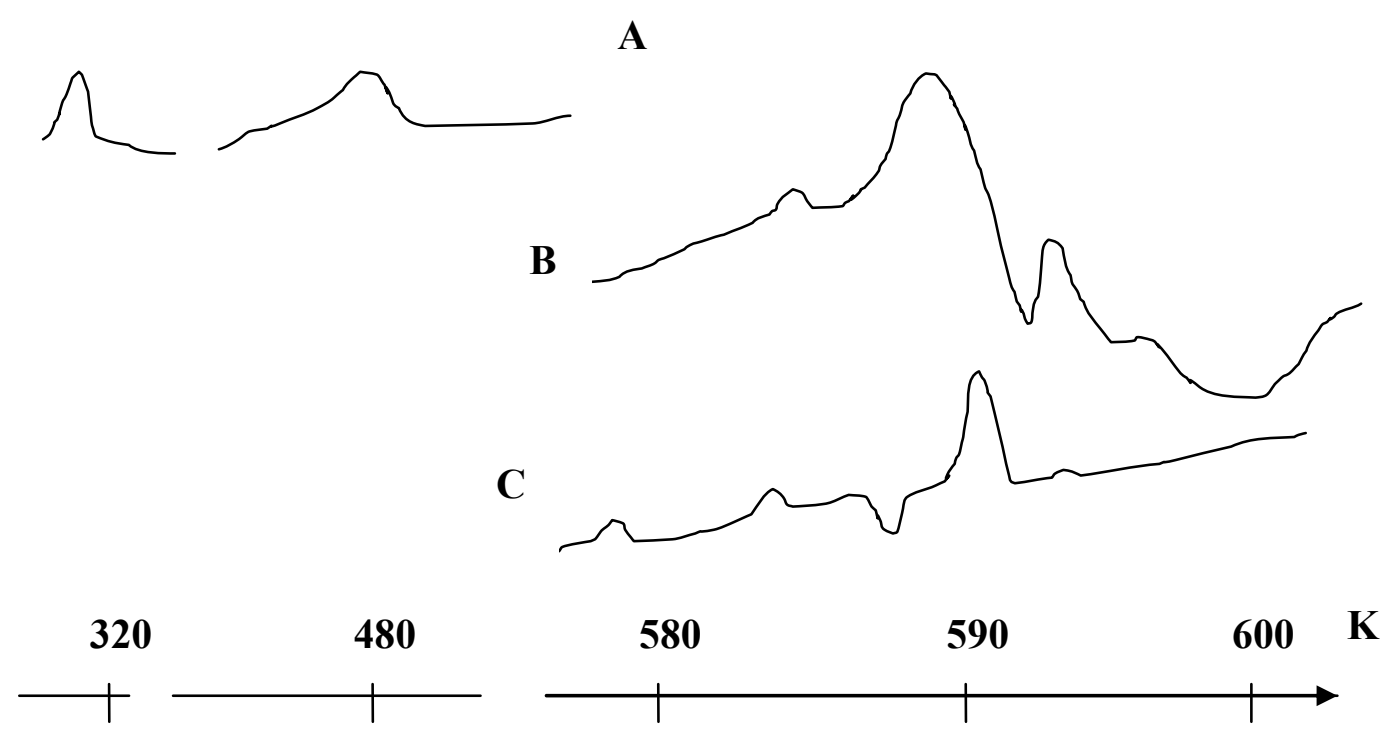

Figure 5. DSC thermograms of compound 5 (A) , $\beta-C D-5$ complex (B), and HPB-5 complex (C).

The observations regarding the thermograms shown in Figures 1-5 indicate the changing of the molecular arrangement in the systems formed by CDs and compounds 1-5, comparatively with the pure steroids used.

\section{Solubility studies}

Figure 6 and 7 show the phase solubility obtained for the compounds $\mathbf{1 ,} 3$ and $\mathbf{4}$ in a mixture solution of water - ethanol (95 - 5), in the presence of $\beta-C D$ and HPB, respectively. We have noticed that the compound $\mathbf{1}$ is more soluble in the presence of CDs than the compounds 3 and 4. The solubility of the compounds 3 and $\mathbf{4}$ are not really enhanced by the CDs. The solubility diagrams obtained for these compounds shown a B-type behaviour. ${ }^{6}$ The initial slope of the solubility phase diagrams show an increase in total steroid concentration as result of complexation. Assuming a complex formation with stoechiometric ratio 1:1, the apparent stability constants $\left(K_{c}\right)$ were calculated from the initial linear slope of phase solubility diagrams, according to equation $(1):^{6}$

$$
K_{c}=\frac{\text { slope }}{\text { intercept }(1-\text { slope })}
$$

The obtained $K_{c}$ values are summarized in Table 2 . 
Table 2. Stability constants $\left(K_{\mathrm{c}}, \mathrm{M}^{-1}\right)$ for steroid complexes with $\beta$-CD and HPB, at $20{ }^{\circ} \mathrm{C}$

\begin{tabular}{ccc}
\hline Compound & $K_{c}(\beta-C D$ system $)$ & $K_{c}($ HPB system $)$ \\
\hline $\mathbf{1}$ & 5 & 6 \\
$\mathbf{3}$ & 3.75 & 38.5 \\
$\mathbf{4}$ & 65.5 & 27.4 \\
\hline
\end{tabular}

For the compound 1 the affinity for the two Cds is the same, and the $K_{c}$ values are close. The compound 3 forms stronger complex with HPB than $\beta-\mathrm{CD}$, while for the compound 4 the stability of the complex is greater for $\beta$-CD. The $K_{c}$ values obtained for the compounds $\mathbf{1}, \mathbf{3}$ and 4 are lower than the values of $K_{c}$ calculated from solubility diagrams for some sterols presented in literature. ${ }^{7,8}$

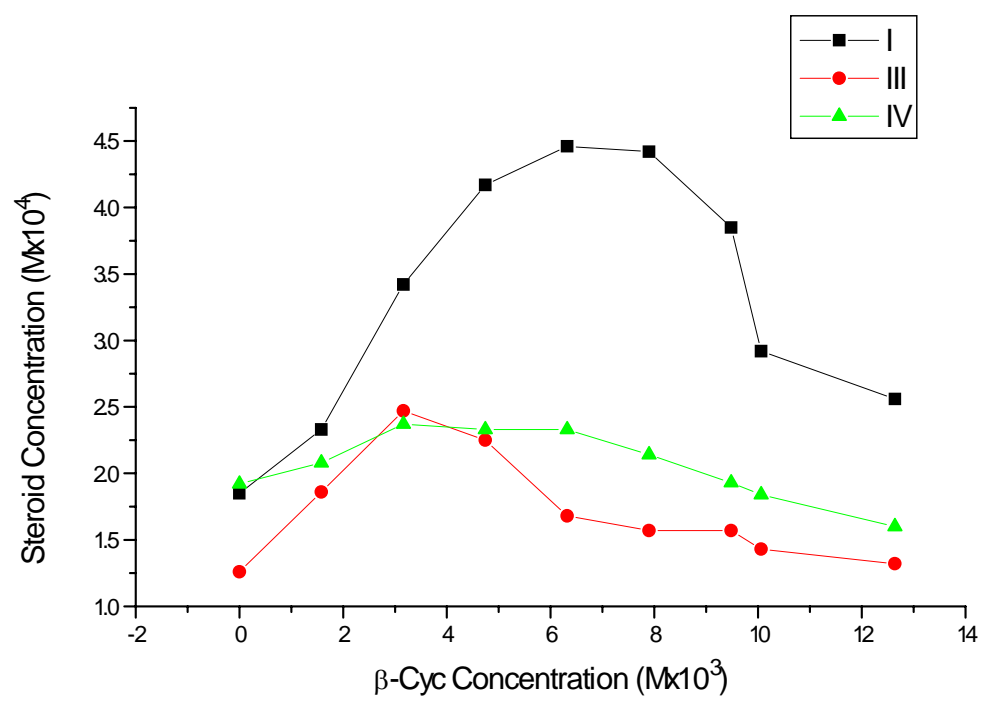

Figure 6. Phase solubility diagrams of compounds 1, 3 and 4 in water - ethanol system, in the presence of $\beta-C D$. 


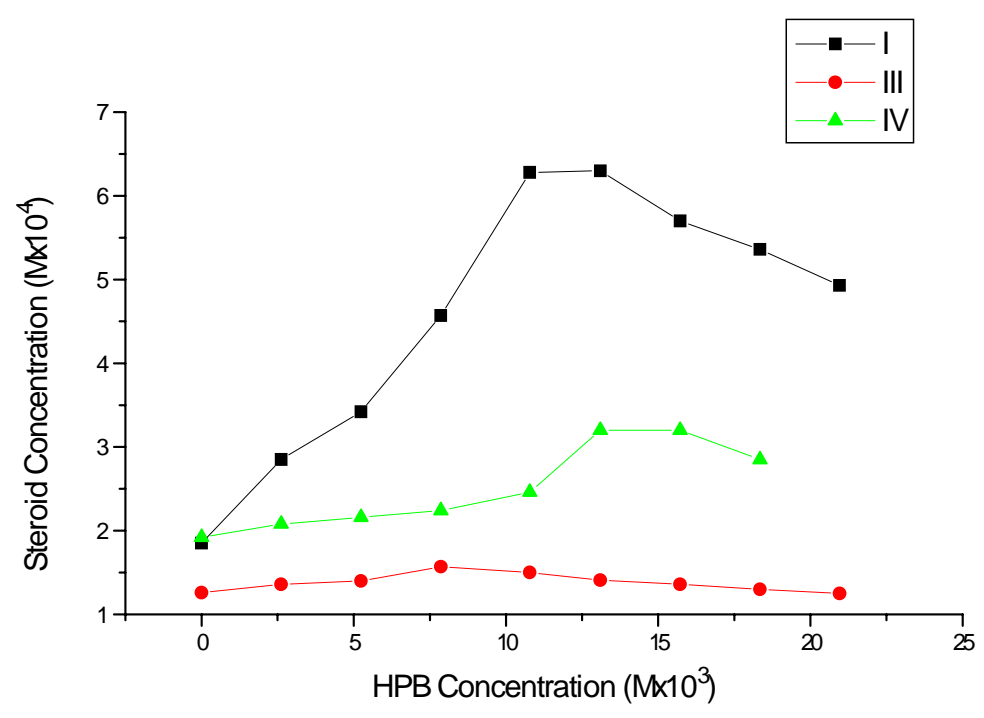

Figure 7. Phase solubility diagrams of compounds 1, 3 and 4 in water - ethanol system, in the presence of HPB.

\section{UV-Vis absorption study}

The solubility study have showed that the steroid derivatives will form soluble complexes in certain range of concentrations (see Figures 6 and 7). These interactions in aqueous solution were further examined by UV-Vis spectroscopy for compounds $\mathbf{1}$ and $\mathbf{3}$. Compound $\mathbf{1}$ exhibited an intense maximum around $250 \mathrm{~nm}$ and the addition of $\beta-C D$ and HPB had an increase of absorbance at this lengthwave. In the case of compound 3 the UV-Vis spectra showed a peak around $330 \mathrm{~nm}$ and a hypercrom effect was observed on the addition of these cyclodextrins. Apparent stability constants $\left(K_{c}\right)$ of $\beta$-CD and HPB complexes with $\mathbf{1}$ and $\mathbf{3}$ were calculated from UV-Vis spectra according with Benesi-Hildebrand equation (2),,${ }^{9,10}$

$$
\frac{\left[G_{\text {total }}\right]}{\Delta A}=\frac{1}{\Delta A_{\max }}+\frac{1}{K_{c}} \frac{1}{\Delta A_{\max }} \frac{1}{\left(\left[C D_{\text {total }}\right]-[C G]\right)}
$$

where $\Delta \mathrm{A}$ is the difference of the absorbance for free and complexed compound, $K_{c}-$ apparent stability constant, $\left[\mathrm{G}_{\text {total }}\right]$-total concentration of guest molecule, [CD $\left.\mathrm{CD}_{\text {total }}\right]$-total concentration of cyclodextrin, [CG] the concentration of complex in solution. From the linear plots of reciprocal $\triangle \mathrm{A}$ vs. reciprocal $\left[\mathrm{CD}_{\text {total }}\right]$ of each cyclodextrin were calculated the stability constants of complexes. The values obtained for these constants are presented in Table 3. 
Table 3. Stability constants $\left(K_{\mathrm{c}}, \mathrm{M}^{-1}\right)$ for steroid complexes with $\beta-\mathrm{CD}$ and HPB calculated from UV data

\begin{tabular}{ccc}
\hline Compound & $K_{c}(\beta-C D$ system $)$ & $K_{c}($ HPB system $)$ \\
\hline I & 272 & 219 \\
III & 14.6 & 524 \\
\hline
\end{tabular}

The values of stability constants obtained from UV-Vis absorbtion data are with one or two order of magnitude greater then those obtained from solubility data. One of the possible explanation consist in the possibility of formation of some inclusion complexes with higher stoechiometry, for which the equations (1) and (2) do not apply.

\section{Experimental Section}

General Procedures. All solvents were purified by distillation before use. Cholesterol and sigmasterol were Merck products; cholesteryl chloroformate, $\beta-\mathrm{CD}$ and HPB were from Aldrich. The purity of the compounds were checked by TLC: for the compounds 1-3 it was used silica gel plates $0.25 \mathrm{~mm}$ (Merck), and as eluent a mixture of petroleum ether : benzene : acetone $4: 1$ : 0.5 ; for compounds 4 and 5 the same stationary phase, eluent benzene : chloroform 9 : 1 ; visualization was done by iodine vapors. The texture and the melting points were determined with a Boetius hot-stage apparatus. The compounds $\mathbf{1}$ and $\mathbf{4}$ were obtained and characterized as previously described, as well as their interactions with CDs. ${ }^{11}$ The IR spectra were recorded with an UR-20 Carl-Zeiss Jena spectrophotometer. The ${ }^{1} \mathrm{H}$ - and ${ }^{13} \mathrm{C}-\mathrm{NMR}$ spectra were recorded on a Varian Gemini 300-BB instrument. All the NMR spectra were performed at room temperature (295 K) using deuterocholoform as solvent and TMS as internal standard; for ${ }^{13} \mathrm{C}-\mathrm{NMR}$ spectra the resonance line of the solvent at $77 \mathrm{ppm}$ was taken as reference line. The ${ }^{13} \mathrm{C}-\mathrm{NMR}$ spectra were run in quantitative conditions: pw 45, $20 \mathrm{~s}$ delay between pulses, acquisition $0.8 \mathrm{~s}$, the decoupler swith only in acquisition period and 2048 transients for each FID. NOE, COSY $\left({ }^{1} \mathrm{H}-\right.$ $\left.{ }^{1} \mathrm{H},{ }^{1} \mathrm{H}-{ }^{13} \mathrm{C}\right)$ and long range $\operatorname{COSY}\left({ }^{1} \mathrm{H}-{ }^{13} \mathrm{C}\right)$ pulse sequences were used for proton and carbon chemical shift assignments. Thermal properties were determined with a Perkin-Elmer DSC 2 calorimeter under argon purge. The temperature was calibrated with the melting point of the standard. The weight of the samples was 3-5 $\mathrm{mg}$, and the heating rate was $10 \mathrm{degree} / \mathrm{min}$. The UV-Vis spectra were measured using a M40 Specord spectrophotometer. All measurements were carried out at $25^{\circ} \mathrm{C}$ using $(9: 1 \mathrm{v} / \mathrm{v})$ solutions.

Stigmasteryl-5'-nitrobenzo[b]-thiophenesulphone-2'-carboxylate 2. A solution of 11 mmol 5nitrobenzo[b]-thiophenesulphone-2-carboxylic acid in benzene $(20 \mathrm{~mL})$ was added dropwise to a solution of $11 \mathrm{mmol} \mathrm{N}, \mathrm{N}$-carbonyldiimidazole in $50 \mathrm{~mL}$ benzene, with stirring. After $30 \mathrm{~min}$ a solution of $10 \mathrm{mmol}$ stigmasterol in $50 \mathrm{~mL}$ benzene is added. The mixture is heated with stirring 
at reflux and monitored by TLC. When the reaction was complete, the solvent was removed and the residue washed with ethanol and then crystallized from a mixture of ethyl acetate and amyl alcohol, resulting white needles. Yield 75\%. TLC $\mathrm{R}_{\mathrm{f}}$ 0.44. IR $\left(\mathrm{CCl}_{4}\right), v \mathrm{~cm}^{-1}: 1700(\mathrm{C}=\mathrm{O}), 1190$ (C-O sim), 1055 (C-O asim). ${ }^{1} \mathrm{H}-\mathrm{NMR}\left(\mathrm{CDCl}_{3}, \delta\right.$ ppm, J Hz): 8.78 (d, 2.1, H-4'); 8.30 (dd, 8.9, 2.1, H-6'); 7.99 (d, 8.9, H-7'); 8.18 (s, H-2'); 5.44 (de, 6.0, H-6); 5.17 (dd, 15.2, 8.4, H.22 or H23); 5.02 (dd, 15.2, H-23 or H-22), 4.80 (m, H/3); 2.4 (m, 28H); 1.08 (s, 3H, $\left.\mathrm{CH}_{3} / 19\right) ; 0.89$ (d, $3 \mathrm{H}, \mathrm{H}-29) ; 0.87$ (d, $3 \mathrm{H}, \mathrm{CH}_{3}-26$ or $\left.\mathrm{CH}_{3}-27,7.1\right) ; 0.81$ (d, $3 \mathrm{H}, \mathrm{CH}_{3}-27$ or $\left.\mathrm{CH}_{3}-26\right) ; 0.80$ (t, $3 \mathrm{H}$, $\mathrm{H}-29) 0.71\left(\mathrm{~s}, 3 \mathrm{H}, \mathrm{CH}_{3}-18\right) .{ }^{13} \mathrm{C}-\mathrm{NMR}\left(\mathrm{CDCl}_{3}, \delta \mathrm{ppm}\right)>161.34(\mathrm{C}-28) ; 147.39(\mathrm{Cq}) ; 145.85$ $(\mathrm{Cq}) ; 139.22(\mathrm{Cq}) ; 138.30(\mathrm{CH}) ; 135.21(\mathrm{Cq}) ; 130.39(\mathrm{CH}) ; 123.59(\mathrm{CH}) ; 123.24(\mathrm{CH}) ; 121.14$ $(\mathrm{CH}) ; 120.84(\mathrm{CH}) ; 76.23(\mathrm{C}-3)$ and for the rest of stigmasteryl, the chemical shifts are similarly with literature.

Sitosteryl-5'-nitrobenzo-[b]-tiophen sulphon-2-carboxylate (3). White-yellow plates, yield 50\%, TLC; petroleum ether: benzene: acetone 4:1:0.5, $\mathrm{R}_{\mathrm{f}} 0.67$. IR $\left(\mathrm{CCl}_{4}\right), v\left(\mathrm{~cm}^{-1}\right): 1710(\mathrm{C}=\mathrm{O})$; 1180 (C-O asim), 1057 (C-O sim). ${ }^{1} \mathrm{H}-\mathrm{NMR}\left(\mathrm{CDCl}_{3}, \delta\right.$ ppm, J, Hz): 8.74 (d, H-4', 2.2); 8.27 (dd, H-6', 8.9, 2.1); 8.13 (s, H-3');7.96 (d, 8.9, H-7'); 5.41 (m, H-6); 4.85 (m, 1H-H-3); 2.49-0.71 (m $-32 \mathrm{H})$ and for the rest of stigmasteryl the chemical shifts are similarly with $2 .{ }^{13} \mathrm{C}-\mathrm{NMR}$ $\left(\mathrm{CDCl}_{3}, \delta \mathrm{ppm}\right)>161.23(\mathrm{C}-28) ; 148.07(\mathrm{Cq}) ; 147.34(\mathrm{Cq}) ; 145.80(\mathrm{Cq}) ; 139.19(\mathrm{Cq}) ; 138.37$ $(\mathrm{Cq}) ; 130.41(\mathrm{CH}) ; 123.53(\mathrm{CH}) ; 121.09(\mathrm{CH}) ; 120.08(\mathrm{CH}) ; 76.14(\mathrm{CH}, \mathrm{C}-3)$ and for the rest of sitosteryl the chemical shifts are similarly with literature.

Cholesteryl-mercaptobenyothiazolyl-2-thiocarbonate (5). A solution of $5 \mathrm{mmol}$ of 2mercaptobenzothiazol and $0.5 \mathrm{~mL}$ of pyridine in $40 \mathrm{~mL}$ of dry benzene was added dropwise with stiring to $5 \mathrm{mmol}$ of cholesteryl chloroformate in $40 \mathrm{~mL}$ of dry benzene. The reaction was monitorised by TLC. When the reaction was complete (until no cholesteryl chloroformate spot was observed in TLC), the benzene solution was washed with cold dilute hydrochloric acid and water, and than dried over anhydrous sodium sulfate. The benzene was removed and the crude product purified by column chromatography and finally crystallized. Yield $50 \%$. TLC benzene : chloroform $9: 1, \mathrm{R}_{\mathrm{f}}$ 0.92. IR $\left(\mathrm{CCl}_{4}\right) \vee\left(\mathrm{cm}^{-1}\right): 1750(\mathrm{C}=\mathrm{O}), 1260\left(\mathrm{C}-\mathrm{O}\right.$ asim); $1070(\mathrm{C}-\mathrm{Osim}) .{ }^{1} \mathrm{H}-$ NMR (CDCl $3, \delta$ ppm, J, Hz): 7.30 (td, 7.4, 1.3, 1H, H-5'); 7.46 (dd, 8.8, 1.5, 1H, H-4'); 7.35 (td, 7.4, 1.8, H-6'); 7.40 (dd, 7.4, 1.3, H-7'); 5.47 (m, 1H, H-6); 4.98 (m, 1H, H-3); 2.50-0.87 (m, 2 $\mathrm{H}$ ); 1.07 (s, 3H, CH3-19); 0.91 (d, 3H, $\mathrm{CH}_{3}-21,6.4$ ); 0.87 (d, 3H, $\mathrm{CH}_{3}-26$ or $\mathrm{CH}_{3}-27,7.1$ ), 0.86 (d, $\left.3 \mathrm{H}, \mathrm{CH}_{3}-27,7.1\right) ; 0.68$ (s, 3H, $\left.\mathrm{CH}_{3}-18\right) .{ }^{13} \mathrm{C}-\mathrm{NMR}\left(\mathrm{CDCl}_{3}, \delta \mathrm{ppm}\right): 168.15$ (C-28); 149.49 $(\mathrm{Cq}) ; 139.45(\mathrm{Cq}) ; 138.69(\mathrm{Cq}) ; 127.57(\mathrm{Cq}) ; 127.18(\mathrm{CH}) ; 125.45(\mathrm{CH}) ; 123.70(\mathrm{CH}) ; 120.93$ $(\mathrm{CH}) ; 113.77(\mathrm{CH}) ; 80.82(\mathrm{C}-3)$ and for the rest of cholesteryl the chemical shifts are similarly with literature.

Preparation of solid probes containing the complexes for thermal analysis. The solid complexes were obtained after evaporation of ethanolic - water solutions of $\beta$-CD or HPB and one of the compounds $\mathbf{1 - 5}$, at $50{ }^{\circ} \mathrm{C}$. The residue obtained was dried to constant weight. Samples 
of compounds 1-5 and their complexes with $\beta-\mathrm{CD}$ or HPB were sealed in aluminium pans and measured at a scanning speed of $10{ }^{\circ} \mathrm{C} / \mathrm{min}$.

Solubility studies. Solubility measurements were carried out according to Higuchi and Connors. Excess amounts of compounds 1, 3 and $\mathbf{4}$ were added to aqueous : ethanol solutions $(95: 5 \mathrm{v} / \mathrm{v})$ containing various concentrations of $\mathrm{CDs}$ and then the samples were shaken at $25{ }^{\circ} \mathrm{C}$. After equilibration was reached (approximately two weeks), an aliquot was filtrated and the sample was analyzed by UV-Vis.

\section{References}

2. Wallimann, P.; Marti, T.; Furer, A.; Fiederich, F. Chem. Rev. 1997, 97, 1567.

3. Englebienne, P. Mol. Aspects. Med. 1984, 7, 313.

4. Uekama, K.; Hirayama, F.; Irie, T. Chem. Rev. 1998, 98, 2045.

5. Duchene, D.; Vaution, C.; Glomot, F. Drug Dev. Ind. Pharm. 1996, 12, 2193.

6. Saenger, W. Inclusion Compounds, Atwood, J. L.; Davies, J. E .D; Macnicol, D. D. Eds; Academic Press: New York, 1984; Vol 2, pp 231-235.

7. Higuchi, T.; Connors, K. A.; Adv. Anal. Chem. Instrum. 1965, 4, 117.

8. Chun, I. K.; Yun, D. S. Int. J. Pharm. 1993, 96, 91.

9. Uekama, K.; Fujinaga, T.; Otagiri, M.; Yamasaki, M. Int. J. Pharm. 1982, 10, 1.

10. Benesi, H. A.; Hildebrand, J. H. J. Am. Chem. Soc. 1949, 71, 2703.

11. Cooper, A.; MacNicol D. D. J.C.J. Chem. Soc., Perkin II 1978, 760.

12. Topala, C.; Ionita, G.; Lavinia, L. Scientific Communication Sesion, Constanta 2000, 4 April, Romania. 